\title{
AN ANALYSIS OF DRIVER REACTIONS TO TIRE FAILURES SIMULATED WITH THE NATIONAL ADVANCED DRIVING SIMULATOR (NADS)
}

\author{
Robert Rucoba, Lee Carr, Robert Liebbe, \& Amanda Duran \\ Carr Engineering, Inc. \\ Houston, Texas, USA \\ Email: Amanda@ceimail.com
}

\begin{abstract}
Summary: Analyses of real-world tire tread belt detachment and/or sudden air loss events as well as vehicle testing of those events have been presented in scientific literature since the 1990's. These confirm that such tire failures are complex and semi-random events that produce numerous sensory feedback cues to real-world drivers. These analyses further demonstrate that vehicles representing a full spectrum of steering characteristics are typically controllable and are controlled by drivers both during and after the tire disablement event. In 2003, the National Highway Traffic Administration (NHTSA) sponsored a study using the National Advanced Driving Simulator (NADS) to evaluate the technical hypothesis that there is a correlation between vehicle linear range understeer gradient and the likelihood of control loss when subject drivers experience a simulated tread belt detachment. The NADS subjects "drove" three simulated "vehicles" with different understeer gradients in a simulated tread separation even. The study's authors reached conclusions regarding the drivers' ability to control the "vehicles" which were inconsistent with real-world research. This paper presents an analysis of the NADS study performed to identify possible causes of the conflicting results and provides commentary upon several deficiencies noted in the NADS vehicle/tire modeling and validation. A more comprehensive understanding of the reported driver reactions when viewed in light of real vehicle experiments, real-world data, and an understanding of the limitations of the simulations is provided.
\end{abstract}

\section{INTRODUCTION}

The National Advanced Driving Simulator (NADS) is a ground-vehicle simulator developed by the National Highway Traffic Safety Administration and Iowa State University. The simulator consists of a dome with a vehicle cab placed inside that is attached to a motorized platform to mimic the vehicle motions. Publications pertaining to simulation modeling, validation methods and validation results of the NADS appeared in the scientific literature in the 1990's. NADS has been used to conduct studies of driver and driving behaviors including driver impairment, young driver performance, driver distraction, and elderly driver performance. No published works other than the one addressing the effects of tire failure are known which demonstrate the usefulness of this tool in evaluating vehicle design characteristics

\section{Past Real-World Research on Tread Separation Events}

In the last two decades, tire disablements, such as a tread separation and/or sudden air loss, and their effects on driver control have been the focus of various research studies and publications. Past research has focused on real-world vehicle testing and analyses of real-world crashes. The 
findings are generally consistent throughout published research (Gardner, 1998; Dickerson, 1999; Klein, 1999; Fay, 1999; Arndt, 2001; Carr, 2001):

- Although a rare event when measured relative to the number of vehicles in operation and the rate at which tire failures are known to present themselves, control loss events do occur . They are known to occur in all vehicle types regardless of make and regardless of the design details of their suspension systems.

- Loss of control following tire failure occurs because some minority of drivers place demands on their vehicle that exceed the vehicle's reduced cornering capacity. The most commonly documented circumstance involves extreme yaw rotation in a final turn with a failed tire on the outside rear position. The underlying cause for control loss is that the decreased tractive capacities of the disabled tire are exceeded by the high cornering demands of these drivers. None of these events are associated with sub-limit or linear range vehicle performance.

- Tests confirm that vehicles with widely varying linear range understeer characteristics retain a maneuvering capacity in excess of $0.4 \mathrm{~g}$ 's on a compatible roadway surface following a rear tire failure. Published studies uniformly demonstrate that vehicles with a rear tire failure remain controllable when the driver demands do not exceed this level.

\section{TECHNICAL HYPOTHESIS VS. REAL-WORLD FINDINGS}

The NADS study entitled "Investigation of Driver Reactions to Tread Separation Scenarios in the National Advanced Driving Simulator (NADS)" evaluated the hypothesis that a correlation exists between the linear range understeer gradient and the likelihood of control loss by drivers exposed to a simulated rear tire tread belt detachment event (Ranney, 2003). In this study, 108 drivers participated in two driving simulations at approximately $75 \mathrm{mph}$; the first being an "unexpected" tread separation event and the second an "expected" tread separation event.

The experimenters started with "baseline” Vehicle 1 which was modeled to represent a small sports utility vehicle that had been previously validated, at least in part, to a real vehicle in certain test track maneuvers. A tire model was created that had reduced cornering stiffness and traction capacities to simulate a failed tire. Vehicles 2 and 3 were modeled by reducing the linear range understeer gradient on the Vehicle 1 model, but no details about the validation of these modifications are provided. The study states: "Vehicle 2 and Vehicle 3 models are not models of real vehicles and should not be referenced to any actual manufactured SUVs"; "the Vehicle 2 and Vehicle 3 model parameter changed from the Vehicle 1 model parameters were not based on any manufactured vehicles"; "vehicles 2 and 3 were hypothetical vehicles and were not intended to represent any particular vehicle make or model”; and "vehicles 2 and 3 were used to explore the influence of changes in the understeer gradient on driver response in maintaining vehicle control. Thus, the ability to generalize the above conclusions to specific vehicles is limited," (emphasis added).

Despite these warnings, Ranney concluded, "Decreasing vehicle understeer was strongly associated with the likelihood of control loss following both the unexpected and expected tire failures.” They further concluded, "Differences associated with vehicle understeer conditions observed in the present study were large and consistent, independent of driver expectations and across driver age groups. It is thus fair to conclude that in the event of a complete rear-tire 
detread, the increased difficulty in vehicle handling and the associated loss of vehicle control with decreasing vehicle understeer generalize to real-world driving," (empasis added). This conclusion is at odds with analyses of real-world crashes and with tests of real-world vehclies.

The understeer gradient for typical passenger cars is within a range of 1.5 to 6.5 degrees/g as shown in Figure 1-Left. If the hypothesis were true, then there would be an over-representation of certain models of vehicles involved in crashes because of their low understeer gradient. Available data shown in Figure 1-Right confirm that this is not true.
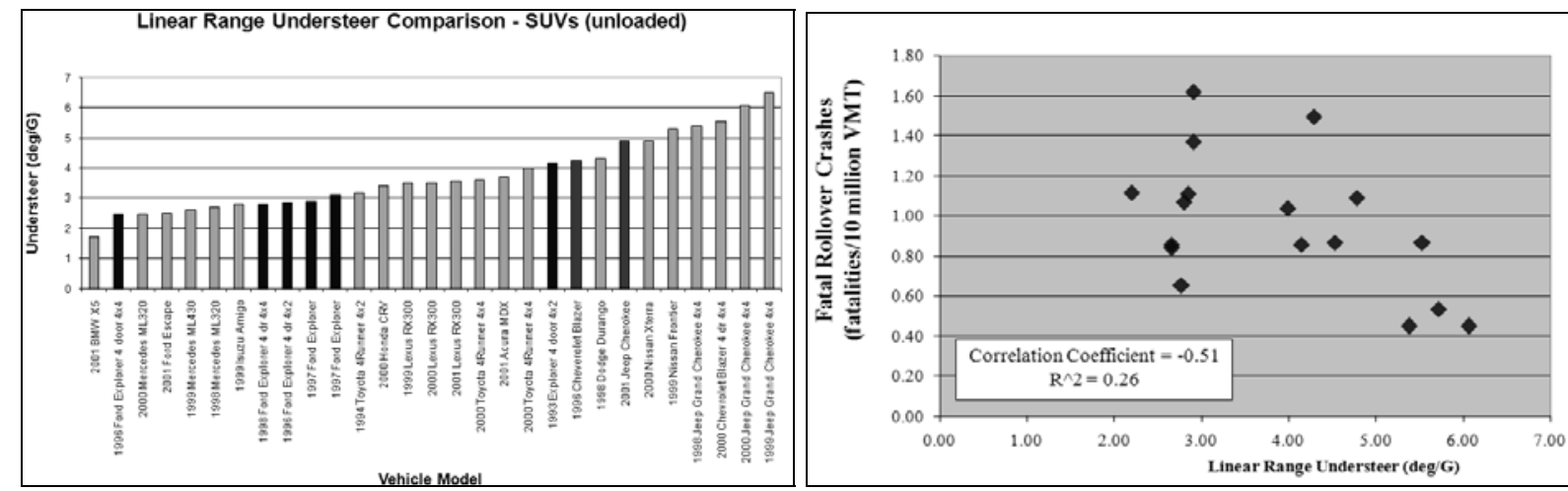

Figure 1. Linear range understeer comparison for various passenger cars (left); Relationship between fatal rollover crashes and linear understeer range (Carr, 2001) (right)

The underlying cause of control loss is that tire traction decreases after tire failure so that forces and moments cannot be balanced for some excessive driver steering demands. It arises through the physics of tire traction and does not arise because of the vehicle design. Testing performed by the authors of this paper confirms that this fundamental cause overwhelms differences in design among vehicle classes or within vehicle classes (Carr, 2001). No known vehicle design can accommodate the reduced tire traction to maintain the margin of safety achieved with intact tires. Reasonable levels of safety are achieved with current technology by providing an appropriate margin of safety in the vehicle's capacities as designed and by limiting the frequency of tread separations and other tire failure modes. All vehicles in the real world exhibit diminished cornering capacity and display oversteer at limit conditions when excessive demands are made by some minority of drivers.

\section{NADS Sensory Feedback Deficiencies}

The Ranney study did not appear to replicate real-world conditions with the regard to sensory feedback. In the 216 experiments, 54 of the tests required the facilitator to "notify" the test driver that they had just experienced a simulated tire de-tread. The paper described that event in the following fashion: "Many subjects were unaware that a tread separation had occurred. Even on the expected trials, some subjects did not immediately interpret the cues appropriately. Many subjects clearly noticed the noise, looked around briefly, and then returned to driving when nothing else occurred," (emphasis added).

If the participant did not respond to the tread separation within 15 seconds for the "unexpected" tests or 10 seconds for the "expected" test, the driver was notified that "You've just experienced 
a tread separation. Drive as you normally would with a tread separation.” The lack of realistic sensory feedback indicates a serious shortcoming in its replication of real-world driving conditions and the realism of the auditory and tactile feedback of the NADS simulator. Other issues are raised by the instruction to "Drive as you normally would with a tread separation" given that no information is provided that would suggest that any of the subjects had ever experienced such an event. That many subjects continued “driving” without problem indicates that maintaining vehicle control posed no true challenge to a majority of the drivers.

The authors of this paper performed numerous instrumented partial and full tread detachment experiments on a variety of real-world vehicles, and found that with either disablement situation, several key sensory feedback cues are consistently provided to the driver. Before the tread's detachment, the increasing separation between the steel belts causes the vehicle to vibrate and shake, accompanied by noise that becomes progressively louder. It also causes extra drag on the side of the vehicle with the separating tire so that some small amount of steering is required to maintain the vehicle's path because of differential longitudinal drag (Tandy, et. al., 2007). When the tread completely detaches from the remainder of the tire, noise and vibration either ceases or diminishes substantially. If the tread partially detaches, measured forces have been observed to be more varied and may be larger than forces caused by full tread detachment.

Similar sensory feedback findings are cited in real-world experiments conducted by others (Gardner, 1998; Dickerson, 1999; Klein, 1999). Faye states, "The events certainly could not be characterized as sudden or without warning”(1999). The simple fact that many subjects did not even notice that the event occurred raises concerns as to the fidelity of the NADS simulator and any human factors conclusions that are reached about loss of control.

\section{Analysis of the NADS Simulator Vehicle \& Tire Models}

The "baseline” model for Vehicle 1 was based on a real-world Jeep Cherokee, and to date, there has been limited documentation in the public domain with regard to the underlying mathematical model. However, the limited documentation that is available raises several concerns regarding its accuracy, particularly with regard to the tire model, which is a critical component in the simulation.

Issue \#1. The Jeep Cherokee mathematical model and its validation process are described in two treatises (Salaani, 1999; Salaani, 2000). Comparing the tire parameter files presented in Salaani (1999) and the "normal" tire parameter files presented in the Ranney paper revealed key differences. At this time, it is uncertain what affect each of the tire parameter changes makes on the tire models. What is certain is that the "validated" normal tire model was not the same normal tire model used in the study.

Issue \#2. Ranney (2007) states, "The parameters used to model the detreaded tire were not based on force and moment machine measurements typically used to generate tire model parameters. The parameters for the detreaded tire were in part generated based on detreaded tire responses presented in the literature”. This methodology deviates from NHSTA's recommended practices. In previous published scientific literature, NHTSA engineers have stated, "Measuring vehicle parameters is a time consuming and sometimes difficult task. Although vehicle parameter estimation schemes are available for many parameters, it is best, especially for simulation validation work, to directly measure all 
parameters.” (Heydinger, 1990). Garrott states, “...each vehicle parameter should be unambiguously defined and methods developed to measure or obtain each value that is input to the simulation” (1997).

Additionally, there are questions regarding the cited sources for the tire parameters in the model. In Dickerson, no detreaded tire data are presented; only vehicle response data are given (1999). In Arndt, no detreaded tire data are presented for the tire modeled on the "baseline" vehicle. Three of the four tires that were tested by Arndt retained both outer and inner belts after manual tread removal, which is inconsistent with the common real-world failure mode in which the tread and outer belt detach from the inner belt and carcass.

A tire force and moment machine measured the characteristics of the same tire as used in the Ranney paper with the tread and outer belt removed. Figure 2 shows the lateral force capacity of the simulated tire was approximately $1 / 3$ of the capacity of the actual tested tires at large slip angles. This results in erroneous vehicle performance characteristics resulting in an artificially low lateral capacity and a model which is artificially prone to loss of control regardless of its linear range understeer gradient. The actual tire's measured characteristics differ so significantly from the model used in the NADS simulation that the study’s conclusions are invalid.

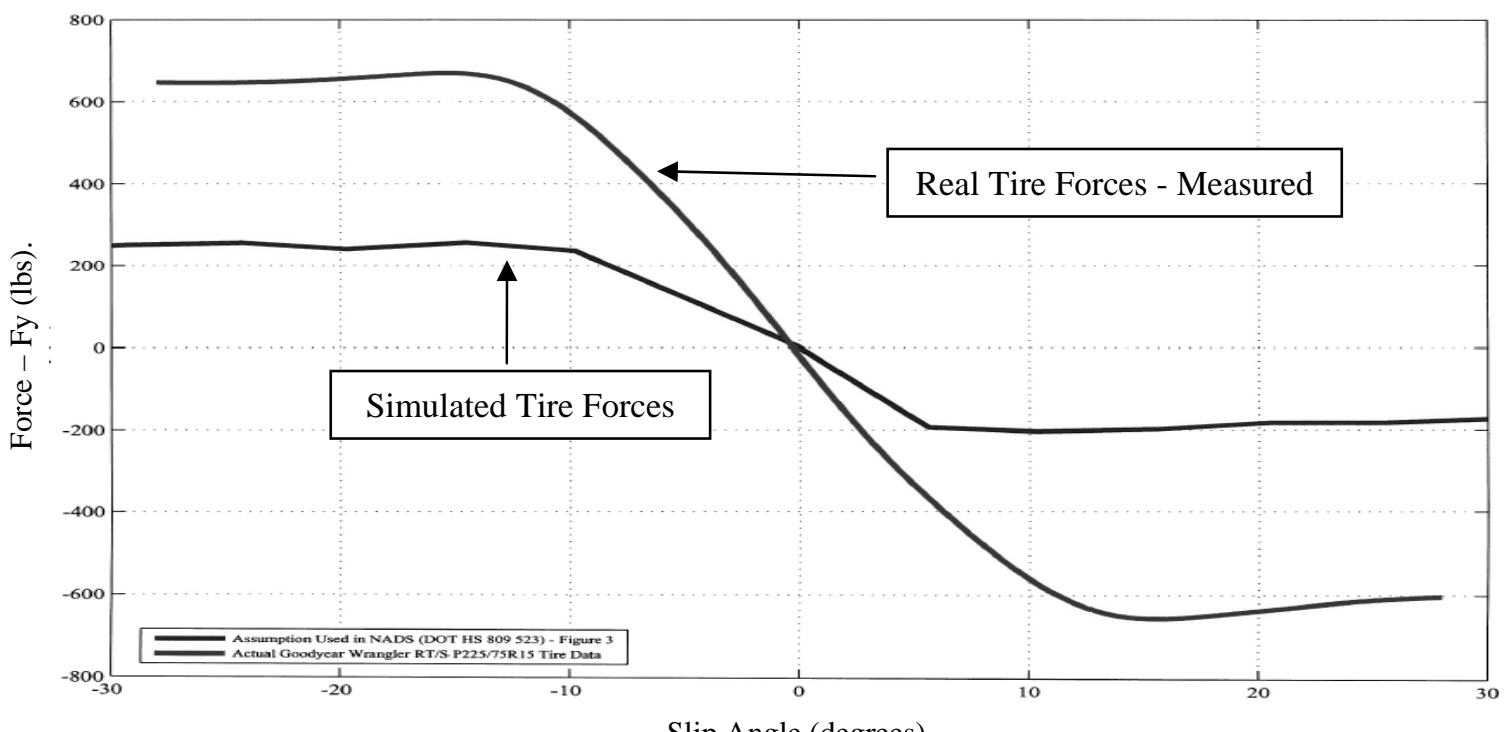

Figure 2. Tire Lateral Forces vs. Slip Angle for Tire with Full Tread Belt Separation at Fz $=750 \mathrm{lbs}$ and Inclination Angle $=0^{\circ}$ - Comparison between test data \& NADS model (Tandy, 2007)

Issue \#3. The Jeep Cherokee mathematical model with intact tires was reportedly "validated" at speeds significantly below the speeds simulated in the Ranney paper. The simulation was conducted at $75 \mathrm{mph}$ and the highest speed cited where the Jeep Cherokee was "validated" was $50 \mathrm{mph}$. Extrapolation of results is not appropriate given that speed affects tire force and moment characteristics (Gillespie, 1992).

\section{Loss of Control Using the NADS Findings}

Throughout the experiments, a substantial number of subjects had to be told they had experienced a tread separation after they had maintained control of the vehicle for 10-15 seconds 
after the detachment. The authors noted, "Many subjects clearly noticed the noise, looked around briefly, and then returned to driving when nothing else occurred," (emphasis added).

In an unusual interpretation of the data, Ranney disregarded the instances where drivers maintained control of their vehicle before being notified. The fact that the drivers were able to maintain control of the simulated vehicle for over 1100 feet before being told that they had experienced a tread separation should not have been disregarded. Table 1 shows the test data as interpreted by Ranney, and Table 2 shows the re-evaluated test data when tallying drivers who maintained control 10 to 15 seconds after tread separation. Even if one ignores the questionable replication of the NADS simulator to real-world tread separation driving conditions, the fact that the vast majority of drivers were able to maintain control of the "baseline" vehicle 1 (the one closest to a real-world vehicle) is consistent with real-world test findings. Table 2 shows that $94 \%$ of the "unexpected" test drivers had no difficulty maintaining control of their "vehicle" after experiencing a simulated tread belt detachment.

Table 1. Vehicle 1 NADS Original Test Data

\begin{tabular}{|c|c|c|c|c|c|}
\hline UNEXPECTED TEST & $\begin{array}{c}\text { Maintain } \\
\text { Control } \\
\end{array}$ & $\begin{array}{c}\text { Lose } \\
\text { Control } \\
\end{array}$ & EXPECTED TEST & $\begin{array}{c}\text { Maintain } \\
\text { Control } \\
\end{array}$ & $\begin{array}{c}\text { Lose } \\
\text { Control } \\
\end{array}$ \\
\hline Brake First & 0 & 0 & Brake First & 25 & 1 \\
\hline Steer First & 13 & 2 & Steer First & 4 & 0 \\
\hline $\begin{array}{l}\text { Drive } 15 \text { seconds before } \\
\text { notification then brake }\end{array}$ & 9 & 1 & $\begin{array}{l}\text { Drive } 10 \text { seconds before } \\
\text { notification then brake }\end{array}$ & 3 & 0 \\
\hline $\begin{array}{l}\text { Drive } 15 \text { seconds before } \\
\text { notification then steer }\end{array}$ & 8 & 3 & $\begin{array}{l}\text { Drive } 10 \text { seconds before } \\
\text { notification then steer }\end{array}$ & 3 & 0 \\
\hline Total - 36 Tests & 30 & 6 & Total - 36 Tests & 35 & 1 \\
\hline Percentage & $83 \%$ & $17 \%$ & Percentage & $97 \%$ & $3 \%$ \\
\hline
\end{tabular}

Table 2. Vehicle 1 NADS Reevaluated Test Data

\begin{tabular}{lcclcc}
\hline UNEXPECTED TEST & $\begin{array}{c}\text { Maintain } \\
\text { Control }\end{array}$ & $\begin{array}{c}\text { Lose } \\
\text { Control }\end{array}$ & EXPECTED TEST & $\begin{array}{c}\text { Maintain } \\
\text { Control }\end{array}$ & $\begin{array}{c}\text { Lose } \\
\text { Control }\end{array}$ \\
\hline Brake First & 0 & 0 & Brake First & 25 & 1 \\
Steer First & 13 & 2 & Steer First & 4 & 0 \\
$\begin{array}{l}\text { Drive 15 seconds before } \\
\quad \text { notification }\end{array}$ & 21 & & $\begin{array}{c}\text { Drive } 10 \text { seconds before } \\
\text { notification }\end{array}$ & 6 & 35 \\
Total - 36 Tests & 34 & 2 & Total - 36 Tests & $97 \%$ & $3 \%$ \\
$\quad$ Percentage & $94 \%$ & $6 \%$ & Percentage & & 1 \\
\hline
\end{tabular}

\section{CONCLUSIONS}

Ranney theorized that, when drivers experienced a loss of vehicle control after a tire failure in the study, the likelihood of control loss can be correlated to the vehicle's understeer gradient. Real-world crash studies and real-world testing show this theory to be incorrect. In addition, realworld testing shows that excessive driver demands that exceed the reduced cornering capacity of the failed tire, not a vehicle design charcteristics, are the likely cause. When the test data are properly reevaluated by focusing on the driver actions immediately following a tread separation, the simulation test data indicates that the overwhelming number of drivers are able to control their vehicle, which is more consistent with real-world findings. This result is apparent even though the NADS simulation lacked proper validation, used non-validated parameter values, and 
lacked accurate sensory feedback to the driver, and most importantly, used a simulated tire with $1 / 3$ of the limit cornering capacity of an actual failed tire.

Ranney specifically caution readers, “Thus, the ability to generalize the above conclusions to specific vehicles is limited. Generalization is also constrained by the assumption that the tire detread event is accurately simulated and that driver responses in the simulator correspond to what they would do in the real-world.” Given that these underlying assumptions are incorrect, the theory itself has not been verifyed by the Ranney study. Any conclusion regarding the effect of understeer gradient cannot be made using this study as a basis and certainly cannot be generalized to real-world driving.

\section{FUTURE WORK}

The authors recommend a more thorough analaysis of the three real world tests used in the study to evaluate their conditions, circumstances, and results so that comparisons to the simulator results can be made. Additional review of any other underlying validation of the Jeep model used as the baseline in the Ranney study is also merited. The authors also recommend that all test notes, test data, videotapes and photographs created as part of the Ranney study be thoroughly analyzed for a more complete understanding of the responses by the drivers.

\section{REFERENCES}

Arndt, M.W., Thorne, M. \& Dickerson, C.P. (2000). Properties of Passenger Car Tires with Tread Detachment. Society of Automotive Engineers. 2000-01-0697.

Arndt, S.M, \& Arndt, M.W. (2001). The Influence of a Rear Tire Tread Separation on a Vehicle’s Stability and Control. . Society of Automotive Engineers. 2001-06-0145.

Carr Engineering, Inc. (2001, June). Vehicle Dynamics Update, NHTSA-Ford Meeting. Washington, DC: Lee Carr.

Dickerson, C.P., Arndet, M.W., \& Arndt, S. M. (1999). Vehicle Handling with Tire Tread Separation. Society of Automotive Engineers. 1999-01-0120.

Fay, R.J., Robinette, R.D., Smith, J., Flood, T., \& Bolden, G. (1999). Drag and Steering Effects from Tire Tread Belt Separation and Loss. Society of Automotive Engineers. 1999-01-0447.

Gardner, J. (1998). The Role of Tread/Belt Detachment in Accident Causation. International Tire Exhibition and Conference. ITEC 1998 Paper 27A.

Garrott, W.R., Grygier, P.A., Chrstos, J.P., Heydinger, G.J., Salaani, K., Howe, J.G., \& Guenther, D.A. (1997). Methodology for Validating the National Advanced Driving Simulator's Vehicle Dynamics (NADSdyna). Society of Automotive Engineers. 970562.

Gillespie, T.D. (1992). Fundamentals of Vehicle Dynamics. Warrendale: Society of Automotive Engineers.

Heydinger, G.J., Garrott, W.R., Chrstos, J.Pp., \& Guenther, D.A. (1990). A Methodology for Validating Vehicle Dynamics Simulations. Society of Automotive Engineers. 900128.

Klein, E.Z. \& Black, T.L. (1999). Anatomy of Accidents Following Tire Disablements. Society of Automotive Engineer. 1999-01-04460. 
Ranney, T. A, Heydinger, G. Watson, G, Salaani, K, Mazzae, E. N., Grygier, P. (2003). Investigation of Driver Reactions to Tread Separation Scenarios in the National Advanced Driving Simulator (NADS). National Highway Traffic Safety Administration. Report No. DOT HS 809 523. Washington, DC: Department of Transportation.

Salaani, M.K., Guenther, D.A., \& Heydinger, G.J. (1999). Vehicle Dynamics Modeling for the National Advanced Driving Simulator of a 1997 Jeep Cherokee. Society of Automotive Engineers. 1999-01-0121.

Salaani, M.K. \& Heydinger, G.J (2000). Model Validation of the 1997 Jeep Cherokee for the National Advanced Driving Simulator. Society of Automotive Engineers. 2000-01-0700.

Tandy, D.F. (2007) [Tire Force and Moment Data: Comparison to NADS Study Model Parameters Used]. Unpublished raw data.

Tandy, D. F, Tandy, K.T., Durisek, N.J., Granat, K.J., Pascaralla, R.J., Carr, L., \& Liebbe, R. L. (2007). An Analysis of Yaw Inducing Drag Forces Imparted During Tire Tread Belt Detachments. Society of Automotive Engineers. 2007-01-0836. 